\title{
Surcharging as a Facilitating Practice
}

\author{
by
}

\author{
Luke Garrod \\ ESRC Centre for Competition Policy and School of Economics, \\ University of East Anglia
}

\section{CCP Working Paper 06-17}

\begin{abstract}
This paper shows how separately itemised surcharges potentially facilitate collusion during a temporary cost shock if firms commit to their duration. A duopoly model with price-matching punishments shows that if firms set higher prices they only receive punishment during the shock because they expect prices to fall in the future regardless of a deviation. When it is likely that costs will fall in the future, the price-matching punishment is too small to increase prices, so firms maintain rigid prices. When it is unlikely that costs will fall the punishment is harsh enough to sustain marginally higher supracompetitive prices. However, if firms commit to surcharges for the shock's duration they are able to set even higher prices, because surcharges effectively commit firms to a price decrease and so threaten a harsher punishment after the cost shock has ended.
\end{abstract}

\section{October 2006}

JEL Classification Codes: L31, L41

Keywords: Surcharge; facilitating practice; collusion

Acknowledgements:

I am grateful to Bruce Lyons for extensive suggestions. Thanks also to Andrew Bugg, Steve Davies, Morten Hviid, Matthew Olczak, Greg Shaffer, Chris Wilson, Julian Wright and seminar participants at the EARIE Conference 2006 for helpful comments. The support of the Economic and Social Research Council is also gratefully acknowledged.

Contact details:

Luke Garrod, Centre for Competition Policy, University of East Anglia, Norwich, Norfolk, NR4 7TJ, UK.

l.garrod@uea.ac.uk 


\section{Introduction}

Separately itemised surcharges have become a common form of pricing for firms in industries that experience temporary cost shocks due to rises in the price of an essential input. Examples of surcharges are observed in the transport industries where many firms have implemented fuel surcharges since the recent unprecedented increases in oil prices; similarly, steel producers implement several different surcharges to cover the costs of fluctuating alloy prices. In many cases firms preannounce the level of their surcharge during its implementation and give some indication of the length of its duration. This paper considers whether 'surcharging' facilitates higher supracompetitive prices during a temporary cost shock.

The motivation of this paper comes from several cartel cases where firms have fixed surcharge levels during temporary cost shocks ${ }^{1}$. In fact the Office of Fair Trading (OFT) is currently investigating British Airways for allegedly fixing the level of its long-haul fuel surcharge with its rivals on Trans-Atlantic flights ${ }^{2}$. The interesting question that this practice raises is: in the presence of low menu costs, why would firms illegally fix price increases and then precariously highlight the act by separately itemising the increase as a surcharge, which could increase the risk of alerting a competition authority? This paper argues that surcharges play a critical role in affecting the incentives of maintaining the collusive agreement.

It is well known that firms' incentives to maintain or break collusive agreements are affected by fluctuations in market conditions. Rotemberg and Saloner (1986) and Haltiwanger and Harrington (1991) find collusion is difficult to sustain when the market is in a boom, because firms' short-term gain from deviating is greatest while the expected loss in future profit is small.

\footnotetext{
1 See Commission Decisions 94/985/EC - Far Eastern Freight Conference - (IV/33.218) [1994] OJ L378/17; Case 1999/243/EC - Trans-Atlantic Conference Agreement - (IV/35.134) [1999] OJ L95/1; Case 2000/627/EC - Far East Trade Tariff Charges and Surcharges Agreement (FETTCSA) IV/34.018 [2000] OJ L268/1. See also Case C-57/02 Compañia española para la fabricacion de aceros inoxidables SA (Acerinox) v EC Commission [2005] 5 CMLR 15.

${ }^{2}$ Office of Fair Trading Statement, OFT investigation into alleged price coordination in relation to long haul passenger flights to and from the UK, 22 June 2006, available at: www.oft.gov.uk
} 
However, empirical studies by Carlton $(1986,1989)$ suggest that prices in more concentrated industries, where collusion is more likely to occur, are less responsive to changes in the market conditions. This evidence leads Carlton (1989) to conjecture that colluding firms are unlikely to vary prices in response to cost changes due to the risk of triggering a price war. In a rare attempt to understand the problem, Athey, Bagwell and Sanchirico (2004) show that tacitly colluding firms may prefer to set rigid prices if they have private information about their own costs.

This paper develops another theoretical model which shows that colluding firms may maintain rigid prices throughout a cost shock. Price rigidity occurs in this model because firms enforce their collusive agreement by matching any price deviation in the future (as described by Lu and Wright, 2005) instead of reverting to the one-shot Nash price in the event of a deviation. In contrast to Athey, Bagwell and Sanchirico's (2004) model where price rigidity exists because of firms' asymmetric information, firms may maintain rigid prices during a period of high costs in this model because of the uncertain future expectation of costs decreasing.

Setting and matching the same prices is widespread in the industries in which firms set surcharges, such as the airline and steel industry where firms are notorious price leaders (Scherer and Ross, 1990). It is also not a new idea theoretically as it is the underlying principle behind firms' punishment strategy discussed by Chamberlin (1929) in the seminal paper on tacit collusion, and the static kinked demand curve (Sweezy, 1939). Lu and Wright (2005) show price matching is a weaker punishment compared to Nash reversion and the even harsher optimal punishment strategies (Abreu 1986, 1988), so firms may not be able to sustain the highest collusive prices in equilibrium, especially as firms' goods become more substitutable. However, price matching is attractive to firms because if there is a breakdown in the collusive agreement it provides higher profit during the punishment phase compared to the other punishment strategies. 
The benchmark model with price-matching punishments is presented in section 3 , which is extended in section 4 by introducing a cost shock with an uncertain end. This shows that firms find it difficult to set higher supracompetitive prices during a temporary cost shock due to the weakness of the punishment strategy. For instance, if higher prices are set, firms will adjust to the original price when costs fall regardless of a deviation, because the deviation price is higher than the original collusive price. Therefore, firms only expect to be punished throughout the cost shock. When it is likely that costs will fall in the future the price-matching punishment is too small to increase prices. However, due to the higher costs there is no incentive to deviate from the original price, and as a result firms maintain rigid prices throughout the cost shock. If it is unlikely that costs will fall in future periods, the punishment is harsh enough to increase prices, but these prices will be lower than the ones firms can set when it is certain costs will remain high forever.

Section 5 shows that surcharges can facilitate supracompetitive prices if firms credibly commit to when they will be removed, because they increase the punishment firms receive if there was a deviation. A surcharge effectively commits the firm to a price decrease when costs fall, and if firms deviate during the cost shock they are still committed to reducing the surcharge when costs fall. This further reduction in price means firms will receive an extra punishment after costs have fallen, which enables firms to set higher supracompetitive prices during the cost shock.

The price-matching punishment strategy is discussed in section 6 and section 7 concludes. But before presenting the model in more detail, section 2 provides a formal definition of surcharges and offers a discussion of some other potential explanations, which are not modelled by the theory and are out of the scope of the current paper. 


\section{Surcharges: Definition and Potential Other Motives}

Firms disaggregate their prices in many situations, so to clarify which type of pricing falls into the realm of this paper the following definition is proposed:

Surcharges are an element of a price for a good that has been separately itemised at the firm's discretion during a cost shock. If firms implement a surcharge added on to a base price, they are said to employ dual component prices. Firms employ single component prices if they set prices without surcharges.

This paper is concerned with surcharges that firms commit to remove at some period in the future. Prominent examples of pre-commitment to surcharge duration can be found in the airline industry where various firms have preannounced certain oil prices which must occur before their surcharge is removed; buyers in the steel industry also know that suppliers adjust alloy surcharges monthly and new levels that become effective are announced a month in advance. Cartels can potentially create private incentives to enforce the commitment to surcharges.

At any given total price there is no difference in the revenue received by a firm that sets a single or dual component price. A surcharge also does not change the nature of the trade for consumers relative to setting a single component price because they are (usually) unavoidable. As such, they are distinct from avoidable 'add-ons' that a consumer can choose to buy from the firm to complement an original purchase (Ellison, 2005). For instance, all consumers pay a fuel surcharge when purchasing a flight, but only some consumers will choose to buy the airline's travel insurance policy add-on, which could be obtained from an alternative supplier.

The usual explanation of why firms implement surcharges is to minimise menu costs from frequent changes to single component prices. Firms may construct surcharges to have significantly smaller menu costs which allow 
them to vary prices more often. Additionally, firms also claim surcharges increase the transparency of price changes and allow them to justify the extra burden of their costs to their buyers ${ }^{3}$. This may increase the acceptability of the price rise, as Kahneman, Knetsch and Thaler (1986) suggest that consumers perceive price increases due to cost rises as 'fairer' than the equivalent price rise due to other factors. This may explain why surcharges are predominantly a cost shock phenomenon and why they are preannounced. For instance, in an experiment, Franciosi et al (1995) find firms that announce profits or costs after a cost shock are able to increase prices to the new equilibrium quicker than firms that make no announcement.

Nevertheless, firms may implement dual component prices to obfuscate their total price for consumers. This could be beneficial for firms for two reasons; firstly, an Air Transport Users Council (AUC) report (2005) suggests that airlines include surcharges in the taxes, fees and charges (TFCs) element of the price to fool consumers into booking online flights with a competitive advertised base fare which has unexpectedly uncompetitive TFCs. Gabaix and Laibson (2006) show that firms may shroud surcharges and add-ons from consumers to be able to set them at higher levels. Secondly, imperfect price transparency can increase the sustainability of supracompetitive prices. Møllegaard and Overgaard (2005) argue that reduced price transparency for consumers decreases the incentive for firms to deviate from a collusive agreement, because consumers will not be aware of the price reduction and so will not switch between firms.

Alternatively, surcharges may be used as a signal to a rival of a firm's intent of which price they will set, which may help firms to tacitly coordinate on the surcharge level and total price. Motta (2004) argues coordination is especially difficult in asymmetric oligopolies where firms have different preferences over a range of prices and as a result they may get stuck at a suboptimal price. However, surcharges must provide some extra benefit to the cartels mentioned above since they explicitly fix price increases. As such, these

\footnotetext{
${ }^{3}$ See BA press release, Fuel surcharge increased, 18 April 2006, available at: www.britishairways.com
} 
cartels may have used surcharges to facilitate collusion. This hypothesis is considered in the remaining sections of this paper.

\section{The Model with Price Matching Punishments}

Consider a duopoly where firm 1 and 2 compete on price to sell differentiated goods. The inverse demand function of firm $i=1,2$ is given by $p_{i}=a-b\left(q_{i}+\gamma q_{j}\right) \quad \forall \mathrm{i} \neq \mathrm{j}$, where $p_{i}$ is firm i's price, and $q_{i}$ and $q_{j}$ are firm i's and j's quantities sold, respectively. The measure of product substitutability in the market $0<\gamma<1$ shows the goods become more substitutable as $\gamma \rightarrow 1$. Firms' marginal costs are constant and equal to $c$. For notational purposes, if a variable is the same for both firms the subscripts are dropped.

As in standard linear models (see Vives, 2000) when prices are sufficiently close both firms will have positive demand. However, if prices differ enough the high price firm will receive no demand whereas the low price firm captures the entire market. Specifically, firm i's demand is:

$$
\begin{aligned}
& q_{i}=\frac{\left(a-p_{i}\right)}{b} \\
& \text { if } \quad 0<p_{i} \leq \frac{-a(1-\gamma)+p_{j}}{\gamma} \\
& =\frac{a(1-\gamma)-p_{i}+\gamma p_{j}}{b(1+\gamma)(1-\gamma)} \quad \text { if } \quad \frac{-a(1-\gamma)+p_{j}}{\gamma}<p_{i}<a(1-\gamma)+\not p_{j} \\
& =0 \quad \text { if } \quad p_{i} \geq a(1-\gamma)+\not p_{j}
\end{aligned}
$$

In the unique symmetric Nash equilibrium, firms' prices are $p^{n}=(a(1-\gamma)+c) /(2-\gamma)$. The unique price that maximises the industry's profit is given by $p^{m}=(a+c) / 2$.

Firms compete in an infinitely repeated game and so they can set supracompetitive prices, $p^{n}<p^{c} \leq p^{m}$. This model differs from traditional 
collusive models by assuming that after a deviation firms follow Lu and Wright's (2005) price-matching punishment, in contrast to reverting to the oneshot Nash price. As such, if firm i sets $p_{i}^{d}<p^{c}$ firm $\mathrm{j}$ will match $p_{j}=p^{d}$ in its next pricing decision. The firms employ a simple trigger strategy in which they match the deviation price forever.

Notice that since firm $\mathrm{j}$ will match a (single-period) price deviation firm $\mathrm{i}$ has an opportunity to employ a multiple-period price deviation, where it deviates in the next stage game by setting $p_{i}^{d d}<p^{d}$ and so on in future stage games until it decides to stop. If firm $\mathrm{i}$ employs a multiple-period price deviation, firm $\mathrm{j}$ continues to passively match each deviation until firm i no longer deviates. At the end of a deviation firms maintain prices forever.

Obviously, matching a rival's price is only a plausible punishment for $p^{n}<p_{i}^{d} \leq \bar{p}^{c}$, where $\bar{p}^{c} \leq p^{m}$ is defined as the highest price that is sustainable under price-matching punishments. For instance, first, if $p_{i}^{d}<p^{n}$, matching firm i's deviation price provides firm i with an incentive to increase its price in the next period. So if $p_{i}^{d}<p^{n}$ assume firms revert to $p^{n}$ forever. Second, if $p_{i}^{d}>\bar{p}^{c}$, matching firm i's deviation price provides firm $\mathrm{i}$ with an incentive to lower its price in the next period. So if $p_{i}^{d}>\bar{p}^{c}$ assume firms revert to $\bar{p}^{c}$.

Under these assumptions Lu and Wright (2005) show that firms can set supracompetitive prices if the collusive price is sustainable by a single-period price deviation. This is the case if:

$$
p^{n}<p^{c} \leq \frac{a(1-\gamma)+c(1-\delta \gamma)}{2-\gamma(1+\delta)} \leq p^{m}
$$

where firms discount future profits by $0<\delta<1$. They show that if prices are sustainable by a single-period price deviation it defines a subgame perfect equilibrium because firms can do no better by employing any finite multiple- 
period and infinite price deviations. This key result is replicated in Appendix A of this paper.

\section{Single Component Prices during a Cost Shock with an Uncertain End}

To model the impact that a temporary cost shock may have in a market, assume in (the present) period $t=0$ an essential input for both firms' products increases in price, which raises both firms' marginal costs equally such that $\hat{c}>0$, where hats on all variables signify that there is high marginal costs; in (the past) $t<0$ firms' marginal costs were $c=0$. Firms expect the input's price and their marginal costs to return to their original position at some period $t>0$, but are unsure when this will occur. It is common knowledge that in each period there is a probability of $0 \leq \theta<1$ that the input's price and the firms' marginal costs will return to their original state ${ }^{4}$. The period in which firms' costs fall (period $T$ ) is finite because the probability that the cost shock will be infinite tends to zero as the number of periods tends to infinity. Once marginal costs have fallen firms expect they will remain that way forever.

Also assume that if there has been no deviation in the past firms are able to coordinate upon the price that gives them the highest profit, given the behaviour of the other firm in each stage game. Therefore, before the cost shock firms set:

$$
\bar{p}^{c}=\frac{a(1-\gamma)}{2-\gamma(1+\delta)}
$$

Proposition 1 shows that if it is unlikely that costs will fall in the future firms set higher prices, but they maintain rigid prices if it is likely that costs will fall in the future, as Carlton (1989) conjectured.

\footnotetext{
${ }^{4}$ For simplicity it is assumed that there is no lag between the reduction in the essential input's price and the firms' marginal costs.
} 
Proposition 1 Let

$$
\hat{\tilde{p}}^{c}=\frac{a(1-\gamma)+\hat{c}(1-\theta \delta \gamma)}{2-\gamma(1+\theta \delta)} \quad \text { and } \quad \hat{\bar{p}}^{c}=\max \left\{\hat{\tilde{p}}^{c}, \bar{p}^{c}\right\} .
$$

Firms will set $\hat{\bar{p}}^{c}$ throughout the cost shock, and $\bar{p}^{c}$ when marginal costs fall.

\section{Proof Appendix B}

Intuitively, there is price rigidity because if firms' cost shock price is $p \leq \bar{p}^{c}$ there is a smaller incentive to deviate compared to no cost shock. At the same prices, due to the higher marginal costs, the initial deviation profit is smaller and firms receive a harsher punishment during the cost shock; and they receive the same punishment when costs fall. Therefore, firms will never deviate from any $p \leq \bar{p}^{c}$ during the cost shock. However, if firms set $p>\bar{p}^{c}$ the incentive to deviate is affected by the future expectation of falling collusive prices, because when costs fall firms will revert to $\bar{p}^{c}$, if $p>\bar{p}^{c}$ in the period before. As such, firms will only receive the price matching punishment during the cost shock from a deviation $p_{i}^{d} \geq \bar{p}^{c}$. When it is likely that costs will fall the expected discounted profit from a deviation is too great to allow firms to set $p>\bar{p}^{c} .{ }^{5}$ If it is likely that costs will remain high in future periods, firms' expected discounted future loss in profit is increased, which enables firms to set $p>\bar{p}^{c}$. Intuitively, there is less incentive to deviate in the present when marginal costs are expected to remain high in the future, as the loss in profit is higher because the cost shock and therefore the punishment phase are likely to be longer.

Figure 1 illustrates the relationship between price, the degree of product substitutability and uncertainty of marginal costs remaining high. The parameter values give a monopoly price before and after the cost shock of

\footnotetext{
${ }^{5}$ Specifically, when $\theta<\theta^{*} \equiv(a \delta \gamma(1-\gamma)-c[2-\gamma(1+\delta)]) /(a \delta \gamma(1-\gamma)-c \delta \gamma[2-\gamma(1+\delta)])$.
} 
$p^{m}=2.5$ and $\hat{p}^{m}=3$, respectively. Before the cost shock firms set $\bar{p}^{c}$. When $\theta=0.4$ during the cost shock, at high and low values of product substitutability (where $\hat{\tilde{p}}^{c}(\theta=0.4)>\bar{p}^{c}$ ) firms are able to increase their price. Price rigidity occurs for the intermediate values of $\gamma$ when $\bar{p}^{c}>\hat{\tilde{p}}^{c}(\theta=0.4)$. However, if the probability that costs remain high each period is $\theta=0.8$, firms are able to set their price higher, and in this case there is no price rigidity for all $\gamma$.

Nevertheless, firms are unable to set as high a price when there is uncertainty of costs falling in the future compared with when it is certain costs will remain high forever: as $\theta \rightarrow 1, \quad \hat{\tilde{p}}^{c} \rightarrow[a(1-\gamma)+\hat{c}(1-\delta \gamma)] /[2-\gamma(1+\delta)]$, which is the highest price firms can sustain through price matching punishments with constant marginal costs $\hat{c}$. Also notice that firms will always set $p \geq \hat{p}^{n}$ : as $\theta \rightarrow 0, \hat{\tilde{p}}^{c} \rightarrow \hat{p}^{n}$. This is intuitive because if $\theta=0$, firms have a dominant strategy to deviate from any $p>\bar{p}^{c}>\hat{p}^{n}$, because they will receive no punishment in the future from $p_{i}^{d}>\bar{p}^{c}$ as costs are certain to fall in the next period and regardless of a deviation they will set $\bar{p}^{c}{ }^{6}{ }^{6}$ Therefore, they will maintain $\bar{p}^{c}$ throughout the cost shock. Yet, if $\hat{p}^{n}>\bar{p}^{c}$ firms will be able to set $\hat{p}^{n}$ as they will be playing their best reply to each other's price and there is no incentive to deviate.

${ }^{6}$ This is even the case if there is a known finite end to the cost shock several periods into the future, because there is still be a dominant strategy to deviate in the shock's last period, so through backwards induction firms will always want to deviate from $p>\bar{p}^{c}$ in every period. 
Figure 1 - The Relationship between Price, Degree of Product Substitutability and Uncertain Cost Shock ( $a=5, c=0, \hat{c}=1$ and $\delta=0.9$ )

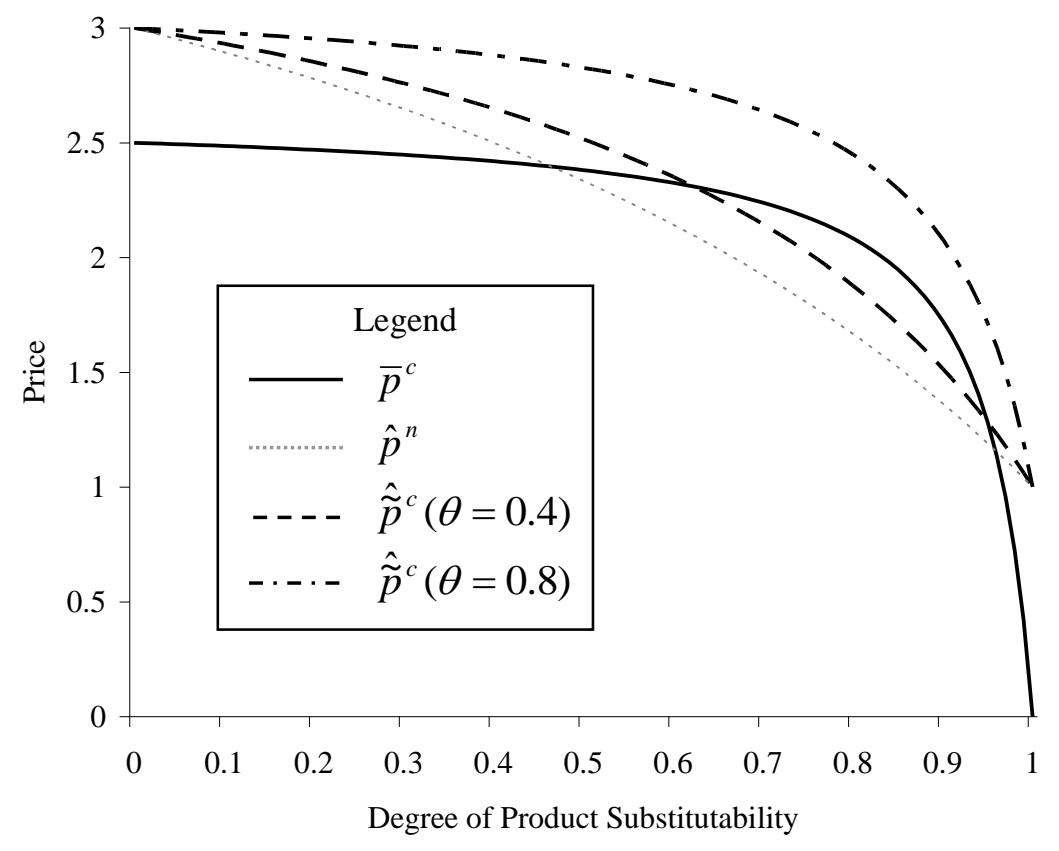

Proposition 1 provides a different result to the common understanding of pricing over business cycles. Rotemberg and Saloner (1986) suggest that if firms sustain collusion by reverting to the one-shot Nash price forever after a deviation, firms find it difficult to sustain collusion when costs are low (demand is high), because there is a greater incentive to deviate during a boom since deviation profits are greater but the expected Nash punishment after the boom remains constant ${ }^{7}$. Proposition 1 suggests that firms find it difficult to sustain collusion when costs are high, because firms have a greater incentive to deviate as the expected punishment in future periods is weaker.

Even if firms are able to commit to prices for the length of the cost shock they cannot set $p>\hat{\bar{p}}^{c}$. If firm $\mathrm{j}$ credibly committed to $p_{j}>\hat{\bar{p}}^{c}$ for multiple periods this only increases firm i's expected profit from deviating because it would receive deviation profits in each period until firm j's commitment ends, and if it set $p_{i}^{d}>\bar{p}^{c}$ it would still not receive any loss in future profit. The next section

\footnotetext{
${ }^{7}$ Although Rotemberg and Saloner (1986) concentrate on demand fluctuations they note that the results can be generalised for cost fluctuations.
} 
considers whether committing to a surcharge enables firms to set higher supracompetitive prices.

\section{Dual Component Prices during a Cost Shock with an Uncertain End}

To consider the ability of dual component prices to facilitate collusion during the cost shock, assume that in the same model described above firms are now able to implement a surcharge with a base price which sum to give the total price. For notational purposes, firm i sets $P_{i}=p_{i}+s_{i}$ when it announces a surcharge $s_{i}>0$, where $P_{i}$ is the firm's total price and $p_{i}$ is the base price.

Figure 2 - Timeline of strategic events in the dual component pricing game

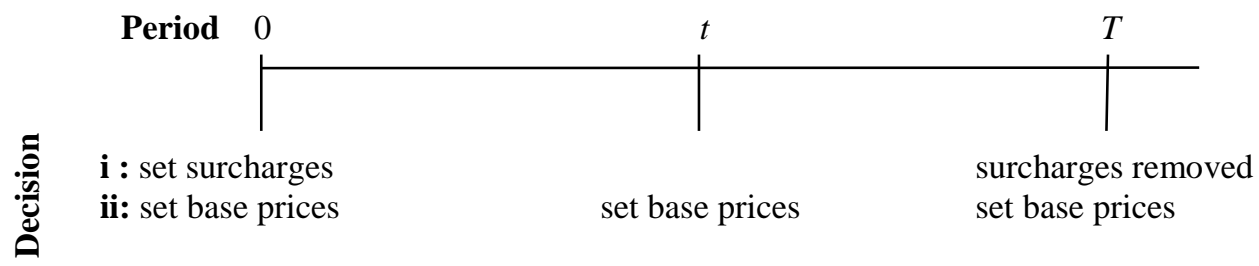

As illustrated by figure 2, the surcharge implementations affect the game in two periods only: when they are implemented and when they are removed. In period $t=0$, there are two sequential decisions: first, firms simultaneously preannounce their surcharges which become common knowledge and commit to remove the surcharge when marginal costs return to their original state. This commitment is achieved by announcing that surcharges will be removed when the essential input's price returns to its original position (which is assumed to be observable) in period $T$. Assume this commitment is credible because if it is broken the consumers' reaction on a firm is too costly on their reputation and sales $^{8}$. Second, firms simultaneously set their base prices. If firms vary their base price during a surcharge implementation, the surcharge commitment remains unchanged. Only the base price decision exists in all

\footnotetext{
${ }^{8}$ Firms can commit to prices in other ways, as discussed in section 2.
} 
$t>0$; but in period $T$ all surcharge commitments expire, so firms firstly removed their surcharges and secondly set prices simultaneously.

Proposition 2 shows that surcharges change the incentives to maintain collusion by threatening a harsher punishment when costs fall, which enables firms to set higher supracompetitive prices during the cost shock.

Proposition 2 Firms are able to set $\hat{p}^{m} \geq P \equiv \hat{p}^{s}+s>\hat{\bar{p}}^{c}$ such that

$$
P=\frac{a(1-\gamma)}{2-\gamma(1+\delta)}+\frac{\hat{c}(1-\delta)(1-\theta \delta \gamma)+2 \delta s(1-\gamma)(1-\theta)}{(1-\theta \delta)[2-\gamma(1+\delta)]}
$$

$\forall 0<\gamma<1$, if and only if $\hat{p}^{s} \leq \bar{p}^{c}$ and $\hat{c}(1-\theta \delta \gamma) /[2-\gamma(1+\theta \delta)]<s \leq \hat{\bar{p}}^{c}$. This maximises the industry's profit when

$$
\hat{\bar{p}}_{i}^{s} \leq \frac{a}{2}-\frac{\gamma(a-\hat{c})(1-\theta \delta)(1-\delta)}{4 \delta(1-\gamma)(1-\theta)}<\bar{p}^{c} \quad \text { and } \quad \frac{\hat{c}}{2}+\frac{\gamma(a-\hat{c})(1-\theta \delta)(1-\delta)}{4 \delta(1-\gamma)(1-\theta)} \leq \bar{s}_{i} \leq \hat{\bar{p}}^{c},
$$

such that $\hat{\bar{p}}_{i}^{s}+\bar{s}_{i}=\hat{p}^{m}$, if and only if $0<\gamma<\gamma^{*}$, for some $0<\gamma^{*}<1$.

\section{Proof Appendix C}

Without surcharges firms would only face punishment throughout the cost shock when firms set $p>\bar{p}^{c}$, but surcharges enable firms to threaten a harsher punishment after the cost shock. For instance, committing to surcharges for multiple periods is effectively a preannouncement of a price decrease when costs return to their original state; during the cost shock firm i could only deviate from $P>\bar{p}^{c}$ by reducing its base price, as firms are committed to the surcharge level until costs fall. Firm $\mathrm{j}$ will match the price in the next period by reducing its base price, which provides the firms with the same punishment as they would receive without a surcharge. However, firms are still committed to reducing their surcharge in period $T$, and so firms will 
only set their base price when costs fall. If the deviation base price is less than the original collusive price firms will receive punishment after the cost shock as well, which allows firms to set higher supracompetitive prices during the shock.

This harsher punishment can only be threaten if firms set base prices such that $\hat{p}^{s} \leq \bar{p}^{c}$. For instance, if firm $\mathrm{j}$ set $\hat{p}^{s}>\bar{p}^{c}$ and $P>\hat{\bar{p}}^{c}$ it provides firm i with a dominant strategy to set $\hat{p}^{s}>\hat{p}_{i}^{d} \geq \bar{p}^{c}$ as firm i will not receive any punishment when costs fall, because when surcharges are removed firms will revert to $\bar{p}^{c}$ since $\hat{p}_{i}^{d} \geq \bar{p}^{c}$. However, when $\hat{p}^{s} \leq \bar{p}^{c}$ firm i's optimal deviation price will be $\hat{p}^{n}<\hat{p}_{i}^{d} \leq \hat{p}^{s}$, which will punish firm i when costs fall, because $\hat{p}_{i}^{d} \leq \bar{p}^{c}$ is sustainable.

Firms are unable to set higher collusive prices when surcharges are too low (when $s<\hat{c}(1-\theta \delta \gamma) /[2-\gamma(1+\theta \delta)]$ ), because they do not threaten a harsh enough punishment when costs fall. As the level of $s$ increases firms are able to sustain higher total prices because the discounted future loss in profit that firms will receive if they deviate increases. Crucially, it is the partial commitment to price that allows firms to set higher prices, because if firm $j$ commits to a surcharge level that is too high, firm i can undercut its surcharge. For instance, if firm j set $s>\hat{\bar{p}}^{c}$ firm i could set $s_{i}=0$ and undercut firm $\mathrm{j}$ for the entire cost shock as firm $\mathrm{j}$ is unable to adjust to a sustainable price until its commitment is over; and if firm i set $p_{i}^{d}>\bar{p}^{c}$ it would still not receive any loss in future profit. This has a similar intuition as why firms cannot set higher collusive prices if they commit to a single component base price for the entire period.

Figure 3 shows the effect surcharging has upon pricing during the cost shock. Using the same parameters as in figure 1, figure 3 shows that firms must set their base price slightly lower than $\bar{p}^{c}$ to sustain the monopoly price during the cost shock. This allows firms to add more of the total price as a surcharge, 
which threatens a sufficiently harsh punishment so firms will not deviate from the monopoly price. With a total price $\hat{\bar{p}}_{i}^{s}+\bar{s}_{i}=\hat{p}^{m}$ set, price is increased by the difference between $\hat{p}^{m}$ and $\bar{p}^{c}$; however, the actual increase that surcharging facilitates is given by the difference between $\hat{p}^{m}$ and $\hat{\bar{p}}^{c}$, as firms could set $\hat{\bar{p}}^{c}$ without surcharges. Firms can only set the monopoly price at $\gamma>\gamma^{*}$ (which is given by the level of $\gamma$ when $\left.\bar{s}=\hat{\bar{p}}^{c}\right)^{9}$ because there is a dominant strategy to deviate from $\bar{s}>\hat{\bar{p}}^{c}$.

Figure 3 - The Relationship between Base Prices, Surcharges and Degree of Product Substitutability $(a=5, c=0, \hat{c}=1, \delta=0.9$ and $\theta=0.8$ )

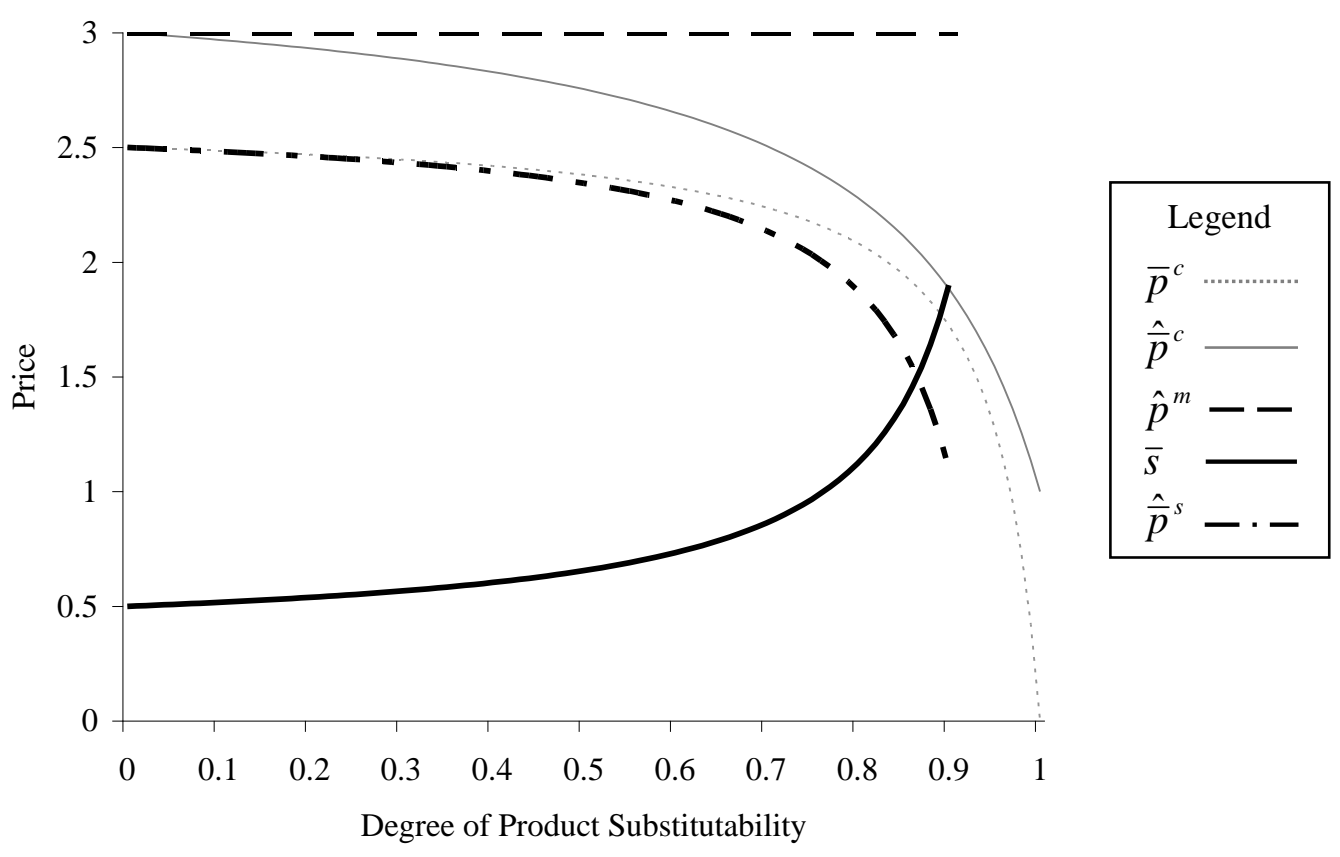

For all $s \leq \hat{\bar{p}}^{c}$ preannouncement rules out any surcharge deviation, as firms can always adjust to the deviation to set a sustainable price in the same period by reducing its base price. But proposition 2 is not dependent upon the preannouncement of surcharge levels, as firms can still set higher prices after the first period of the cost shock. In the first period without preannouncement firms would have an incentive to deviate from any $P>\hat{\bar{p}}^{c}$ and therefore firms would not be able to set higher collusive prices. However, firms could still set

${ }^{9}$ This is calculated in terms of the model's parameters in appendix C. 
a surcharge within $P=\hat{\bar{p}}^{c}$, which would become common knowledge when consumers observe prices. In the second period firms would be able to set higher supracompetitive prices depending upon the surcharge level they set.

Higher supracompetitive prices can also be sustained if firms commit to surcharges for a length of time that is shorter than or equal to the cost shock. In this case if a firm deviated the harsher punishment may begin before the cost shock has ended, which increases the expected discounted loss in profit further and allows lower surcharges to facilitate higher prices. But obviously higher supracompetitive prices cannot be sustained when the surcharges are removed, unless another is implemented. This shorter commitment may be especially beneficial to firms when they expect their costs to fluctuate in the future to allow them to adjust their price with changing costs.

\section{Discussion of the Price Matching Punishment Strategy}

Pre-game theory, there was a widespread belief that firms match rivals' prices during price wars. More recently there is some anecdotal evidence of this behaviour (Slade, 1990; and Levinstein, 1997). Nevertheless, a limitation of this model could be that the results are dependent upon firms employing a price-matching punishment strategy. For example, in contrast to this paper's model, firms can sustain the monopoly price if they revert to the one-shot Nash price for a number of periods in the event of a deviation and are sufficiently patient.

However, price-matching is, in our view, a tenable alternative to Nash reversion. Loosely, we can consider a collusive agreement maintained by price matching as an industry where firms do not react aggressively during price wars, whereas Nash reversion describes as an industry where cooperation quickly degenerates to vigorous competition. In theory terms not enough is known about how tacitly colluding firms initially develop their punishment strategies, and in what situations they are likely to react weakly or 
aggressively to deviations. It may be the case that matching price during price wars becomes a focal point for firms that commonly set the same prices when adjusting price upwards ${ }^{10}$. Alternatively, firms may use price-matching as a 'rule of thumb' when they are uncertain of their rivals' marginal costs and oneshot Nash prices are difficult to calculate. However, firms clearly face a tradeoff between price-matching and Nash reversion: although threatening a harsh punishment can sustain higher prices, if collusion was susceptible to break downs firms may prefer weaker punishments to receive higher profit during the punishment phase. Future research should consider under what circumstances firms prefer to behave aggressively or weakly during price wars. This paper does not describe how firms developed their price matching punishment strategy, just that there is a situation where firms enforce their collusive agreement weakly.

In a world where firms employ weaker punishments, surcharges may facilitate collusion in contrast to Nash reversion for two reasons. First, firms set supracompetitive prices after a deviation to allow surcharges to threaten harsher punishments when costs fall. Second, independent of the market conditions, the punishment strategy is not harsh enough to sustain the monopoly level when firms discount the future. As such, surcharges could be redundant in markets where firms react aggressively when rivals break the collusive agreement.

Nevertheless, if firms behaved less aggressively in the past, threatening a harsher punishment during the cost shock is not a substitute to implementing surcharges, unless firms are willing to invest in their reputation to become more aggressive. For instance, if in the past, firms' price-matching punishment has evolved over repeated interaction; firms know that threatening a harsher punishment during a cost shock is simply cheap talk: if firm $\mathrm{j}$ were to set price at the monopoly level during the cost shock firm $\mathrm{i}$ will

\footnotetext{
${ }^{10}$ As discussed above, firms in the airline and steel industry (in which surcharges are a common form of pricing) have long histories of price leadership, and so it may be more likely that these firms price match during price wars.
} 
deviate, because firm $\mathrm{j}$ will match the price rather than reverting to the oneshot Nash price because its expected discounted profit is higher.

Cartels are a different matter as the firms could explicitly communicate to quickly enforce and coordinate on a new punishment strategy that may enable it to set prices at the monopoly level. However, surcharges may still be a less complex alternative when implementing a new punishment strategy is difficult, which may be the case when cartels are in their infancy ${ }^{11}$. Nevertheless, surcharging could be a more risky option as separately itemising the illegally fixed price increase could potentially increase the likelihood that a competition authority will investigate.

\section{Conclusion}

Implementing surcharges has become a common form of pricing for firms and cartels when they experience a marginal cost shock. There are a range of possibilities that may explain why firms prefer to set dual component prices, ranging from increasing transparency to obfuscation strategies. This paper has considered the potential anticompetitive effects of the practice when firms commit to their surcharge for a period of time.

A collusive duopoly model shows that firms find it difficult to set higher supracompetitive prices during a temporary exogenous cost shock if they set single component prices and follow price-matching punishments. If it is likely that costs will fall in the future, firms have an incentive to deviate from a price which is higher than the original collusive price, as prices are likely to fall in the future regardless of a deviation. As such, firms only receive punishment during the cost shock, so firms' expected future loss in profit from a price-

\footnotetext{
${ }^{11}$ It is interesting to note that firms in the alloy surcharge case (see Acerinox, supranote 1) and to-date BA have not been accused of forming a cartel before their cost shocks. Thus, the cost shock possibly made explicit communication more appealing as it enabled firms to firstly fix the level of the price increase and secondly determine the punishment strategy. Since the cartels were newly formed implementing surcharges may have been the easier option to maintain the higher prices compared with changing their punishment strategy.
} 
matching punishment is smaller compared to when costs are likely to remain high. Therefore, firms are restricted in the level of price they can set.

However, if firms commit to surcharges they effectively commit to price decreases in the future. This threatens a harsher punishment when costs fall if firms were to deviate during the cost shock, because a price deviation only decreases the level of the price further when surcharges are removed. If the level of the surcharge is high enough, firms' future expected discounted loss from deviating will be great enough to allow firms to set higher supracompetitive prices during the cost shock.

Future work should further consider the likely nature of why firms implement surcharges. Ideally, this research will empirically test whether firms in an industry set higher prices with surcharges during a cost shock compared to when there are no surcharges implemented. However, it is unlikely that such a data set that provides a clean, simple, natural experiment will exist. As such, the author's ongoing work is examining the incidence of surcharges across different industries and observing whether the firms that use them also preannounce their surcharge levels and when they will be removed. This may provide an indication of whether firms use surcharges to facilitate collusion and, if so, how widespread the practice may be. 


\section{$\underline{\text { References }}$}

Abreu, D. (1986) "Extremal Equilibria of Oligopolistic Supergames," Journal of Economic Theory, 39, 191-225

Abreu, D. (1988) "On the Theory of Infinitely Repeated Games with Discounting," Econometrica, 56, 383-396

AUC Report (2005) "Taxes, Fees and Charges: An AUC Report on Pricing on Airlines' Websites" available at: www.auc.org.uk

Athey, S, Bagwell, K. and Sanchirico, C. (2004) "Collusion and Price Rigidity," Review of Economic Studies, Blackwell Publishing, 71(2), 317-349

Carlton, D. (1986) "The Rigidity of Prices," American Economic Review, 76(4), 637-658

Carlton, D. (1989) "The theory and the facts of how markets clear: Is industrial organization valuable for understanding macroeconomics?" in Schmalensee, R. and Willig, R. Handbook of Industrial Organization, Oxford, North-Holland

Chamberlin, E. (1929) "Duopoly: Value when Sellers are Few," Quarterly Journal of Economics, 44, 63-100

Ellison, G. (2005) "A Model of Add-on Pricing," Quarterly Journal of Economics, 120 (2), 585-637

Franciosi, R; Kujal, P; Michelitsch, R; Smith, V; and Deng, G. (1995) "Fairness: Effect on Temporary and Equilibrium Prices in Posted-Offer Markets," Economic Journal, 105, 938-50

Gabaix, X. and Laibson, D. (2006) "Shrouded Attributes, Consumer Myopia, and Information Suppression in Competitive Markets," Quarterly Journal of Economics, 121 (2), 505-540

Haltiwanger and Harrington (1991) "The Impact of Cyclical Demand Movements on Collusive Behavior," RAND Journal of Economics, 22(1), 89106

Kahneman, D; Knetsch, J. and Thaler, R. (1986) "Fairness as a Constraint on Profit Seeking: Entitlements in the Market," American Economic Review, 76 (4), 728-741

Levinstein, M. (1997) "Price Wars and the Stability of Collusion: a Study of the Pre-World War I Bromine Industry," Journal of Industrial Economics, 45, 117137

Lu, Y. and Wright, J. (2005) "Tacit Collusion with Price Matching Punishments" available at SSRN: http://ssrn.com/abstract=825285 
Møllegaard, P. and Overgaard, P. (2005) "Information Exchange, Market Transparency and Dynamic Oligopoly," Chapter 62 in Issues in Competition Law and Policy Collins, W. D.

Motta, M. (2004) Competition Policy : Theory and Practice, Cambridge University Press

Rotemberg, J. and Saloner, G. (1986) "A Supergame-Theoretic Model of Price Wars during Booms," American Economic Review, 76, 390-407

Scherer, F.M. and Ross, D. (1990) Industrial Market Structure and Economic Performance, Boston, Houghton Mifflin Company

Slade, M. (1990) "Strategic pricing models and interpretation of price-war data," European Economic Review, 34, 524-537

Sweezy, P. (1939) "Demand Under Conditions of Oligopoly," Journal of Political Economy, 47, 568-573

Vives, X. (2000) Oliogoply Pricing: Old Ideas and New Tools, MIT Press. 


\section{Appendix}

This appendix contains the replication of Lu and Wright's (2005) key result in Appendix $A$, and the proof of proposition 1 and 2 in appendix $B$ and $C$, respectively. We shall begin the appendix by considering firm i's single-period best response to firm j's price $p_{j}$ and both firms have a surcharge $s$ added ( $s=0$ for Appendix A and $\mathrm{B}$, but positive otherwise). This provides us with the constraints on each of the maximisation problems in the appendices below. Firm i's best response function is:

$$
\begin{aligned}
& p_{i}^{d}=\frac{a(1-\gamma)+\not p_{j}-s(2-\gamma)+c}{2} \quad \text { if } \quad p_{j} \leq p^{\prime} \\
& =\frac{p_{j}+s(1+\gamma)-a(1-\gamma)}{\gamma} \quad \text { if } \quad p^{\prime}<p_{j}<p^{\prime \prime} \\
& =\frac{a+c-2 s}{2} \quad \text { if } \quad p_{j} \geq p^{\prime \prime}
\end{aligned}
$$

where

$$
p^{\prime} \leq\left[a(1-\gamma)(2+\gamma)+\gamma c+3 s^{2}\right] /\left(2-\gamma^{2}\right)
$$

and $p^{\prime \prime} \geq[a(2-\gamma)+\gamma c-2 s(1+\gamma)] / 2$. Therefore, given firm $\mathrm{j}$ sets $p^{n}<p_{j}+s \leq p^{m}$, firm i will maximise its present discounted value profit function subject to $\underline{p} \leq p_{i}^{d} \leq p_{j}$, where $\underline{p}$ is defined as:

$$
\underline{p}=\max \left\{\left[a(1-\gamma)+\not p_{j}+c-s(2-\gamma)\right] / 2,\left[p_{j}+s(1+\gamma)-a(1-\gamma)\right] / \gamma\right\}
$$

\section{Appendix A: Replication of Lu and Wright (2005)}

Marginal cost is constant and equal to $c$. Assume firm $\mathrm{j}$ sets some $p^{n}<p^{c} \leq p^{m}$, consider firm i's optimal single-period price deviation $p_{i}=p_{i}^{d}$. Below is the present discounted value of profits from a single-period price deviation: 


$$
\pi_{i}=\left[\frac{a(1-\gamma)-p_{i}+\gamma p^{c}}{b(1+\gamma)(1-\gamma)}\right]\left(p_{i}-c\right)+\frac{\delta}{1-\delta}\left[\frac{a-p_{i}}{b(1+\gamma)}\right]\left(p_{i}-c\right)
$$

where the first term is the profit firm i receives from its initial deviation and the second term is the profit from firm $\mathrm{j}$ matching firm i's deviation price forever. Maximising this profit function with respect to $p_{i}$ subject to $p \leq p_{i} \leq p^{c}$ gives firm i's optimal single-period price deviation:

$$
p_{i}=\frac{a(1-\gamma)+(1-\delta) \gamma p^{c}}{2(1-\delta \gamma)}+\frac{c}{2}
$$

If firm i's optimal price $p_{i}=\hat{p}^{c}$, then it is sustainable by a single-period price deviation. Firm i's optimal single-period price deviation is equal to the collusive price if:

$$
p^{n}<p^{c} \leq \frac{a(1-\gamma)+c(1-\delta \gamma)}{2-\gamma(1+\delta)}
$$

but less than otherwise.

Given $p^{c}$ is sustainable by any a single-period price deviation then it is sustainable by any finite multiple price deviation. For instance, the last period of a finite multiple-period price deviation is a single-period price deviation from $p^{n}<p<p^{c}$, which from above is not profitable. Consequently, through backwards induction every period's deviation will not be profitable.

Now consider an infinite price deviation. Firm i's present discounted value of profit from setting a deviation in each period with firm $\mathrm{j}$ matching each deviation price is given by:

$$
\pi_{i 0}\left(p_{0}, p^{c}\right)+\delta \pi_{i 1}\left(p_{1}, p_{0}\right)+\delta^{2} \pi_{i 2}\left(p_{2}, p_{1}\right)+\ldots
$$

where $p_{t}$ is firm i's optimal price deviation in period $t$ and each price deviation is constrained by $p^{c} \geq p_{0} \geq p_{1} \geq \ldots$ and so on. Maximising firm i's 
present discounted value of profit with respect to each period's deviation price gives a sequence of Euler equations of the form:

$$
\frac{\partial \pi_{i}\left(p_{t+1}, p_{t}\right)}{\partial p_{t+1}}+\delta \frac{\partial \pi_{i}\left(p_{t+2}, p_{t+1}\right)}{\partial p_{t+1}}=0
$$

for all $t \geq 0$. In the linear demand case $\pi_{i}\left(p_{t+1}, p_{t}\right)+\delta \pi_{i}\left(p_{t+2}, p_{t+1}\right)$ is:

$$
\left[\frac{a(1-\gamma)-p_{t+1}+\gamma p_{t}}{b(1+\gamma)(1-\gamma)}\right]\left(p_{t+1}-c\right)+\delta\left[\frac{a(1-\gamma)-p_{t+2}+\gamma p_{t+1}}{b(1+\gamma)(1-\gamma)}\right]\left(p_{t+2}-c\right)
$$

Maximising this with respect to $p_{t+1}$ provides us with the linear second-order difference equation:

$$
a(1-\gamma)+c(1-\delta \gamma)-2 p_{t+1}+\not p_{t}+\delta \gamma p_{t+2}=0 .
$$

The solution to this difference equation is

$$
p_{t}=\frac{a(1-\gamma)+c(1-\delta \gamma)}{2-(1+\delta) \gamma}+A_{1}\left[\frac{1+\sqrt{1-\delta \gamma^{2}}}{\delta \gamma}\right]^{t}+A_{2}\left[\frac{1-\sqrt{1-\delta \gamma^{2}}}{\delta \gamma}\right]^{t}
$$

where $A_{1}$ and $A_{2}$ are two constants. It must be that $A_{1}=0$ since prices are bounded above $p^{c}$ and $\left(1+\sqrt{1-\delta \gamma^{2}}\right) / \delta \gamma>1$. It is also the case that $p_{0}=p^{c}$, thus solving for $A_{2}$ provides us with the solution

$$
p_{t}=\frac{a(1-\gamma)+c(1-\delta \gamma)}{2-(1+\delta) \gamma}+\left[p^{c}-\frac{a(1-\gamma)+c(1-\delta \gamma)}{2-(1+\delta) \gamma}\right]\left[\frac{1-\sqrt{1-\delta \gamma^{2}}}{\delta \gamma}\right]^{t}
$$

where $0<\left(1-\sqrt{1-\delta \gamma^{2}}\right) / \delta \gamma<1$. This implies $p^{c} \geq p_{1}$ if and only if

$$
p^{c} \leq \frac{a(1-\gamma)+c(1-\delta \gamma)}{2-\gamma(1+\delta)}
$$


which is the same constraint that rules out a single-period price deviation, and therefore, all

$$
p^{n}<p^{c} \leq \frac{a(1-\gamma)+c(1-\delta \gamma)}{2-\gamma(1+\delta)} \leq p^{m}
$$

are sustainable through price matching punishments.

\section{Appendix B: Proof of Proposition 1}

First, consider firms' optimal prices when $c=0$ after the cost shock. If there is no deviation we know from Appendix A that firms will set $\bar{p}^{c}$ which is the highest price sustainable through price matching punishments. If there is a deviation $p_{i}^{d}>\bar{p}^{c}$, by assumption firms will set $\bar{p}^{c}$; if $p_{i}^{d} \leq \bar{p}^{c}$, firms will set $p_{i}^{d}$

Now consider firms' optimal prices when $\hat{c}>0$ during the cost shock. Assume firm j sets some $\hat{p}^{n}<\hat{p}^{c} \leq \hat{p}^{m}$, consider firm i's optimal single-period price deviation $p_{i}=\hat{p}_{i}^{d}$. If $\bar{p}^{c}<p_{i} \leq \hat{p}^{c}$ firm i only needs to be concerned with the punishment it will receive before costs return to normal, because firms will revert to $\bar{p}^{c}$ when costs fall. The expected present discounted value of profit from such a single-period price deviation is:

$\pi_{i}=\left[\frac{a(1-\gamma)-p_{i}+\hat{p}^{c}}{b(1+\gamma)(1-\gamma)}\right]\left(p_{i}-\hat{c}\right)+\frac{\theta \delta}{1-\theta \delta}\left[\frac{a-p_{i}}{b(1+\gamma)}\right]\left(p_{i}-\hat{c}\right)+\frac{(1-\theta) \delta}{(1-\delta)(1-\theta \delta)}\left[\frac{a-\bar{p}^{c}}{b(1+\gamma)}\right] \bar{p}^{c}$

where $\bar{p}^{c}<p_{i} \leq \hat{p}^{c}$ and the first term is the profit firm i receives from its initial deviation; the second and third terms are the expected profit from firm $\mathrm{j}$ matching firm i's deviation price forever with $\theta$ probability of high costs and $1-\theta$ probability of low costs in each period, respectively. Maximising this profit function with respect to $p_{i}$ subject to $\bar{p}^{c}<p_{i} \leq \hat{p}^{c}$ gives firm i's optimal single-period price deviation: 


$$
p_{i}=\frac{a(1-\gamma)+(1-\theta \delta) \hat{p}^{c}}{2(1-\theta \delta \gamma)}+\frac{\hat{c}}{2}
$$

This is equal to the collusive price if:

$$
\bar{p}^{c}<\hat{p}^{c} \leq \frac{a(1-\gamma)+\hat{c}(1-\theta \delta \gamma)}{2-\gamma(1+\theta \delta)}
$$

but less than otherwise.

Now consider whether firm i could do better by setting a single-period price deviation such that $p_{i} \leq \bar{p}^{c}$. In this case, when costs return to normal firms will set $p_{i}$ forever and so the expected present discounted value of profit from a single-period price deviation is:

$\pi_{i}=\left[\frac{a(1-\gamma)-p_{i}+\hat{p}^{c}}{b(1+\gamma)(1-\gamma)}\right]\left(p_{i}-\hat{c}\right)+\frac{\theta \delta}{1-\theta \delta}\left[\frac{a-p_{i}}{b(1+\gamma)}\right]\left(p_{i}-\hat{c}\right)+\frac{(1-\theta) \delta}{(1-\delta)(1-\theta \delta)}\left[\frac{a-p_{i}}{b(1+\gamma)}\right] p_{i}$

where $\underline{p}<p_{i} \leq \bar{p}^{c}$ and the only change from the previous profit function is the third term includes $p_{i}$ instead of $\bar{p}^{c}$. Maximising this profit function with respect to $p_{i}$ subject to $\underline{p}<p_{i} \leq \bar{p}^{c}$ gives firm i's optimal single-period price deviation, which is equal to the collusive price for all values of $\hat{p}^{n}<p_{i} \leq \bar{p}^{c}$. Therefore, the highest price that is sustainable by a single-period price deviation is:

$$
\hat{\bar{p}}^{c}=\max \left\{\frac{a(1-\gamma)+\hat{c}(1-\theta \delta \gamma)}{2-\gamma(1+\theta \delta)}, \bar{p}^{c}\right\}
$$

Again through backwards induction, if $\hat{\bar{p}}^{c}$ is sustainable by a single-period price deviation then it is sustainable by any finite multiple-period price deviation. Similarly, an infinite price deviation is also not feasible, because 
firms will cease their price deviation when costs fall. For instance, when costs fall all $p^{n}<p_{i} \leq \bar{p}^{c}$ are sustainable and if $p_{i}>\bar{p}^{c}$ firms will revert to $\bar{p}^{c}$; if $p_{i} \leq \bar{p}^{c}$ firms can sustain $p_{i}$. Therefore, an infinite price deviation is only feasible if costs remain high forever, but this probability tends to zero as the number of periods tends to infinity.

Thus, in the unique subgame perfect equilibrium, firms will set $\hat{\bar{p}}^{c}$ throughout the cost shock, and will set $\bar{p}^{c}$ when marginal cost falls.

\section{Appendix C: Proof of Proposition 2}

First, consider firms' optimal prices when $c=0$ after the cost shock. Similar to Appendix $\mathrm{B}$, if there is no deviation we know that firms will set $\bar{p}^{c}$. If there is a deviation during the cost shock, firms are committed to the level of their surcharge and so firm $\mathrm{j}$ can only match firm i's price by reducing its base price. Therefore, when costs fall and surcharges are removed, firms will set $\bar{p}^{c}$, if $p_{i}^{d} \geq \bar{p}^{c}$; and $p_{i}^{d}$, if $p_{i}^{d}<\bar{p}^{c}$. If costs fall in the period after a deviation, the above results hold because firms sequentially remove their surcharges before prices are matched ${ }^{12}$.

Consider firm i's optimal single-period base price deviation $p_{i}=\hat{p}_{i}^{d}$ if firm j sets some $\hat{p}^{n}<\hat{p}^{s}+s \leq \hat{p}^{m}$ during the cost shock where firms set the same surcharge $s$. First, assume firm i's single-period base price deviation is $\bar{p}^{c}<p_{i} \leq \hat{p}^{s}$. Below is the expected present discounted value of profit from a single period base price deviation:

$$
\pi_{i}=\left[\frac{a(1-\gamma)-p_{i}+\hat{p}^{s}-s(1-\gamma)}{b(1+\gamma)(1-\gamma)}+\frac{\theta \delta}{1-\theta \delta}\left(\frac{a-p_{i}-s}{b(1+\gamma)}\right)\right]\left(p_{i}+s-c\right)+\frac{(1-\theta) \delta}{(1-\delta)(1-\theta \delta)}\left[\frac{a-\bar{p}^{c}}{b(1+\gamma)}\right] \bar{p}^{c}
$$

\footnotetext{
12 If surcharge removal is not sequential firm j may technically want to match firm i's total price when costs fall in the period after a deviation, as it is the price of the last stage game. In this case if $P>\bar{p}^{c}$ there is a probability $(1-\theta)$ that firms will not receive punishment from the deviation in future periods. However, this simply increases the complexity of the probability in the firm i's expected discounted present value profit function without affecting the main result.
} 
where $\max \left\{\bar{p}^{c}, p\right\}<p_{i} \leq \hat{p}^{s}$. As before, the first term is the profit firm i receives from its initial deviation; the second and third terms are the expected profit from firm $\mathrm{j}$ matching firm i's deviation price forever with $\theta$ probability of high costs and $1-\theta$ probability of low costs in each period, respectively. Maximising this profit function with respect to $p_{i}$ subject to $\max \left\{\bar{p}^{c}, p\right\}<p_{i} \leq \hat{p}^{s}$ gives firm i's optimal single-period base price deviation:

$$
p_{i}=\frac{a(1-\gamma)+(1-\theta \delta) \hat{p}^{s}-s[2-\gamma(1+\delta)]}{2(1-\theta \delta \gamma)}+\frac{\hat{c}}{2}
$$

which is equal to the collusive price if:

$$
\bar{p}^{c}<\hat{p}^{s} \leq \frac{a(1-\gamma)+\hat{c}(1-\theta \delta \gamma)}{2-\gamma(1+\theta \delta)}-s
$$

but less than otherwise. Therefore, the highest sustainable $\hat{p}^{s}+s$ is exactly the same as $\hat{\bar{p}}^{c}$ if $p_{i}>\bar{p}^{c}$. Therefore, if firm i can set a single-period base price deviation $p_{i}>\bar{p}^{c}$ firms cannot set higher collusive prices when firms implement surcharges.

Now consider the case when firm i sets a single-period base price deviation such that $\underline{p}<p_{i} \leq \bar{p}^{c}$. The expected present discounted value of profit from a single-period base price deviation is given by:

$\pi_{i}=\left[\frac{a(1-\gamma)-p_{i}+\hat{p}^{s}-s(1-\gamma)}{b(1+\gamma)(1-\gamma)}+\frac{\theta \delta}{1-\theta \delta}\left(\frac{a-p_{i}-s}{b(1+\gamma)}\right)\right]\left(p_{i}+s-\hat{c}\right)+\frac{(1-\theta) \delta}{(1-\delta)(1-\theta \delta)}\left[\frac{a-p_{i}}{b(1+\gamma)}\right] p_{i}$

where the only change from the previous profit function is the third term includes $p_{i}$ instead of $\bar{p}^{c}$. Maximising this profit function with respect to $p_{i}$ subject to $\underline{p}<p_{i} \leq \bar{p}^{c}$ gives firm i's optimal single-period base price deviation: 


$$
\hat{p}^{s}=\frac{a(1-\gamma)+\gamma(1-\delta) \hat{p}^{c}}{2(1-\delta \gamma)}+\frac{\hat{c}(1-\delta)(1-\theta \delta \gamma)-s(1-\delta)[2-\gamma(1+\theta \delta)]}{2(1-\delta \gamma)(1-\theta \delta)}
$$

which is equal to the collusive base price if:

$$
\hat{p}^{s} \leq \frac{a(1-\gamma)}{2-\gamma(1+\delta)}+\frac{\hat{c}(1-\delta)(1-\theta \delta \gamma)-s(1-\delta)[2-\gamma(1+\theta \delta)]}{(1-\theta \delta)[2-\gamma(1+\delta)]} \leq \bar{p}^{c}
$$

Notice that $\hat{p}^{s} \leq \bar{p}^{c}$ can only be true if $s \geq \hat{c}(1-\theta \delta \gamma) /[2-\gamma(1+\theta \delta)]$. Therefore, given this constraints, all $p^{s} \leq \bar{p}^{c}$ are sustainable by a single-period base price deviation. Through backwards induction we can again rule out finite multiple-period base price deviations, and infinite price deviations are again not feasible.

Given firms will optimally set $\hat{p}^{s} \leq \bar{p}^{c}$, consider whether firm i can deviate through setting $s_{i}<s$ in the first decision of stage 0 (recall firms cannot deviate during the cost shock because they are committed to $s$ until costs fall). Since firms' surcharge level becomes common knowledge before firms' base price decision, firms cannot profitably deviate if $s \leq \hat{\bar{p}}^{c}$ : if firm i set $\hat{c}(1-\theta \delta \gamma) /[2-\gamma(1+\theta \delta)] \leq s_{i}<s$, firm j will simply insert $s_{i}=s$ in (5) above to set its base price and avoid a deviation. Therefore, firms will sustain a lower price, as such the deviation will not be profitable. Alternatively, if firm i deviated by setting $s_{i}<\hat{c}(1-\theta \delta \gamma) /[2-\gamma(1+\theta \delta)]$, both firms would set a base price given by (4) such that $\hat{p}_{i}^{s}+s_{i}=\hat{\bar{p}}^{c}$, which again is a lower sustainable price. Notice, however, that firms can only revert to $\hat{\bar{p}}^{c}$ if $s \leq \hat{\bar{p}}^{c}$. If firm $\mathrm{j}$ set $s>\hat{\bar{p}}^{c}$ firm i could set $s_{i}<s$ and $p_{i}>\bar{p}^{c}$ such that $p_{i}+s_{i}<s$. As such, firm i would receive deviation profits until costs fall because it would be unable to match firm i's price until its surcharge commitment expired. Firm i would receive no loss in future profit when costs fall because $p_{i}>\bar{p}^{c}$. 
Therefore, adding a surcharge to the base price in (5) shows firms will be able to set higher supracompetitive total prices, $P$ :

$$
\hat{\bar{p}}^{c}<\frac{a(1-\gamma)(1-\theta \delta)+\hat{c}(1-\delta)(1-\theta \delta \gamma)+2 \delta s(1-\gamma)(1-\theta)}{(1-\theta \delta)[2-\gamma(1+\delta)]} \leq \hat{p}^{m},
$$

if and only if $p_{i} \leq \bar{p}^{c}, \hat{c}(1-\theta \delta \gamma) /[2-\gamma(1+\theta \delta)]<s \leq \hat{\bar{p}}^{c}$. This is true for all $0<\gamma<1$, because by substituting in $s=\hat{c}(1-\theta \delta \gamma) /[2-\gamma(1+\theta \delta)]$ shows:

$$
\hat{\bar{p}}^{c}<P \equiv \frac{a(1-\gamma)}{2-\gamma(1+\delta)}+\frac{\hat{c}(1-\theta \delta \gamma)}{2-\gamma(1+\theta \delta)}
$$

$\forall 0<\delta<1$ and $0 \leq \theta<1$.

To find the surcharge level and base price level that maximises profit, simply substitute $P=(a+\hat{c}) / 2$ which is the industry's profit maximising price into $P$ above to solve for:

$$
\hat{\bar{p}}_{i}^{s} \leq \frac{a}{2}-\frac{\gamma(a-\hat{c})(1-\theta \delta)(1-\delta)}{4 \delta(1-\gamma)(1-\theta)} \quad \text { and } \quad \bar{s}_{i}>\frac{\hat{c}}{2}+\frac{\gamma(a-\hat{c})(1-\theta \delta)(1-\delta)}{4 \delta(1-\gamma)(1-\theta)}
$$

such that $\hat{\bar{p}}_{i}^{s}+\bar{s}_{i}=\hat{p}^{m}$, which given the constraints is only true if and only if $0<\gamma \leq \gamma^{*}$, where $0<\gamma^{*}<1$ is given by

$$
\gamma^{*}=\frac{-y-\sqrt{y^{2}-4 x z}}{2 x}
$$

where for $\bar{p}^{c}>\hat{\tilde{p}}^{c}$,

$$
\begin{aligned}
& x=(a-\hat{c})(1+\delta)(1-\delta)(1-\theta \delta)+2 \delta(1-\theta)[2 a-\hat{c}(1+\delta)] \\
& y=-2(a-\hat{c})(1-\theta \delta)(1-\delta)-2 \delta(1-\theta)[4 a-\hat{c}(3+\delta)] \\
& z=4 \delta(1-\theta)(a-\hat{c})
\end{aligned}
$$

and for $\hat{\tilde{p}}^{c}>\bar{p}^{c}$, 


$$
\begin{aligned}
& x=(a-\hat{c})(1-\delta)(1+\theta \delta)(1-\theta \delta)+2 \delta(1-\theta)(2 a-\hat{c}(1-\theta \delta) \\
& y=-2(a-\hat{c})(1-\theta \delta)(1-\delta)-2 \delta(1-\theta)[4 a-\hat{c}(1-\theta \delta)] \\
& z=4 a \delta(1-\theta) .
\end{aligned}
$$

It can been seen in both cases that $0<\gamma^{*}<1$, because $2 x>|y|, y<0$ and $|y|>\sqrt{y^{2}-4 x z}$. 